OPEN ACCESS

Edited by:

Brigitte Lamy,

University of Montpellier, France

Reviewed by:

Ashok K. Chopra,

University of Texas Medical Branch,

USA

Sabela Balboa Méndez,

University of Sheffield, UK

*Correspondence:

Beatriz Novoa

virus@iim.csic.es

tThese authors have contributed equally to this work.

Specialty section:

This article was submitted to

Aquatic Microbiology,

a section of the journal

Frontiers in Microbiology

Received: 09 May 2016

Accepted: 20 September 2016

Published: 04 October 2016

Citation:

Romero A, Saraceni PR, Merino $S$, Figueras A, Tomás JM and Novoa $B$ (2016) The Animal Model Determines the Results of Aeromonas Virulence

Factors. Front. Microbiol. 7:1574 doi: 10.3389/fmicb.2016.01574

\section{The Animal Model Determines the Results of Aeromonas Virulence Factors}

\author{
Alejandro Romero ${ }^{1+}$, Paolo R. Saraceni ${ }^{1+}$, Susana Merino ${ }^{2}$, Antonio Figueras ${ }^{1}$, \\ Juan M. Tomás ${ }^{2}$ and Beatriz Novoa ${ }^{1 *}$
}

'Department of Immunology and Genomics, Marine Research Institute-Consejo Superior de Investigaciones Cientificas,
Vigo, Spain, ${ }^{2}$ Department of Microbiology, Faculty of Biology, University of Barcelona, Barcelona, Spain

The selection of an experimental animal model is of great importance in the study of bacterial virulence factors. Here, a bath infection of zebrafish larvae is proposed as an alternative model to study the virulence factors of Aeromonas hydrophila. Intraperitoneal infections in mice and trout were compared with bath infections in zebrafish larvae using specific mutants. The great advantage of this model is that bath immersion mimics the natural route of infection, and injury to the tail also provides a natural portal of entry for the bacteria. The implication of T3SS in the virulence of $A$. hydrophila was analyzed using the AH-1::aopB mutant. This mutant was less virulent than the wild-type strain when inoculated into zebrafish larvae, as described in other vertebrates. However, the zebrafish model exhibited slight differences in mortality kinetics only observed using invertebrate models. Infections using the mutant $\mathrm{AH}-1 \Delta$ vapA lacking the gene coding for the surface S-layer suggested that this protein was not totally necessary to the bacteria once it was inside the host, but it contributed to the inflammatory response. Only when healthy zebrafish larvae were infected did the mutant produce less mortality than the wild-type. Variations between models were evidenced using the $\mathrm{AH}-1 \Delta \mathrm{rm} \mathrm{B}$, which lacks the O-antigen lipopolysaccharide (LPS), and the $\mathrm{AH}-1 \Delta$ wahD, which lacks the O-antigen LPS and part of the LPS outer-core. Both mutants showed decreased mortality in all of the animal models, but the differences between them were only observed in injured zebrafish larvae, suggesting that residues from the LPS outer core must be important for virulence. The greatest differences were observed using the $\mathrm{AH}$ $1 \Delta$ FlaB-J (lacking polar flagella and unable to swim) and the $\mathrm{AH}-1:$ :motX (non-motile but producing flagella). They were as pathogenic as the wild-type strain when injected into mice and trout, but no mortalities were registered in zebrafish larvae. This study demonstrates that zebrafish larvae can be used as a host model to assess the virulence factors of $A$. hydrophila. This model revealed more differences in pathogenicity than the in vitro models and enabled the detection of slight variations in pathogenesis not observed using intraperitoneal injections of mice or fish.

Keywords: animal model, zebrafish larvae, rainbow trout, mice, Aeromonas, virulence factors, in vivo infection, mutant Aeromonas 


\section{INTRODUCTION}

Aeromonas hydrophila is a Gram-negative, motile, rod-shaped bacterium widely distributed in aquatic environments (Janda and Abbott, 2010). It is the most common opportunistic species of Aeromonas that causes infections in humans. Transmission to humans occurs mainly by water because its natural residence in aquatic environments favors its appearance in drinking water and food. Infections of $A$. hydrophila produce gastrointestinal disorders (Chopra and Houston, 1999). Additionally, infections caused by the exposure of opened wounds to contaminated water resulted in cellulitis of the subcutaneous tissues (Janda and Abbott, 2010). Immunocompromised people with cancer, hepatic diseases, diabetes or trauma have a higher risk of developing sepsis and fatal A. hydrophila infections (Parker and Shaw, 2011). Other animals, such as other mammals, birds, reptiles, amphibians, and fish, can also be infected (Fulton, 1965; Esterabadi et al., 1973; Cipriano et al., 1984; Gray, 1984; Glunder and Siegmann, 1989; Rodríguez et al., 2008; Hill et al., 2010; Schadich and Cole, 2010). In many freshwater fish species (e.g., carp, catfish, eels, and golden fish), it produces motile haemorrhagic septicaemia (MAS), which causes high mortality rates in aquaculture farms and, in turn, large economic losses (Cipriano et al., 1984). A. hydrophila is naturally present in the gut microbiota of zebrafish (Cantas et al., 2012), and it has been able to generate acute infection in adults (Rodríguez et al., 2008) and embryos (Saraceni et al., 2016) under controlled experimental conditions. A. hydrophila is also infective in invertebrates, such as crustaceans (Jiravanichpaisal et al., 2009), mealworms (Noonin et al., 2010) and unicellular organisms such as Dictyostelium amoebae (Froquet et al., 2007).

The main pathogenic factors associated with Aeromonas are surface polysaccharides (capsule, lipopolysaccharide, and glucan), S-layers, iron-binding systems, exotoxins, extracellular enzymes, secretion systems, fimbriae and other non-filamentous adhesins, motility and flagella (see review by Tomás, 2012).

In the last few years, numerous in vitro and in vivo experiments have been conducted to analyze the specific role of each virulence factor in the pathogenesis of A. hydrophila, using several mutant strains and purified/recombinant toxins. In vitro studies have used cell lines to evaluate the immune response triggered by $A$. hydrophila by measuring phagocytosis and respiratory bursts (Fadl et al., 2007; Reyes-Becerril et al., 2011). In addition, several bacterial phenotypes related to adhesion and invasion of cells, serum resistance and cytotoxic activity have also been evaluated (Merino et al., 1997; Vilches et al., 2007). The great limitation of these in vitro experiments is the lack of the tissue context that definitely influences the evolution of the infection.

In vivo study of Aeromonas virulence factors has classically been conducted in mice because their immune defense system is similar to that of humans. In this model, the bacterium is usually parenterally administered by intramuscular or intraperitoneal injection (Sha et al., 2005; Yu et al., 2005; Chen et al., 2014) or orally by deposition of the bacteria in water (Wong et al., 1996). Injection routes of infection afford the bacteria full access to the animal without the involvement of modified virulence factors. The use of new animal models is being explored (Froquet et al.,
2007) because vertebrate animal models of infection are costly and have raised ethical issues. Moreover, the results from mice cannot be applied to bacteria that infect cold-blooded vertebrates living at low temperatures.

Invertebrate host models have been developed and are being used to study the virulence of human bacterial pathogens (Kurz and Ewbank, 2007; O'Callaghan and Vergunst, 2010). The species used range from terrestrial invertebrates, such as nematodes and insects, to freshwater and marine life, including planarians, crustaceans, molluscs, and many others. In particular, the nematode Caenorhabditis elegans and insects such as the greater wax moth Galleria mellonella and the fruit fly Drosophila have been used to identify the virulence factors of Pseudomonas aeruginosa (Lutter et al., 2008; Garvis et al., 2009; Ramarao et al., 2012) and to analyze clinical isolates of human bacteria (see review O'Callaghan and Vergunst, 2010). Invertebrates such as Pacifastacus leniusculus (crayfish), Tenebrio molitor larvae (mealworms), and even the unicellular organisms Acanthamoeba castellanii and Dictyostelium discoideum amoebae (Froquet et al., 2007; Noonin et al., 2010) have also proved useful for studying bacteria virulence factors (Goy et al., 2007; Kurz and Ewbank, 2007).

Aeromonas hydrophila and A. veronii are the predominant bacterial flora in the gut of the leech, where they play essential roles for the animal in the digestion of blood (Bickel et al., 1994). Human soft tissue infections with this bacterium have been increasing due to the use of medicinal leeches (Hirudo medicinalis and $H$. verbana) for the treatment of venous congestion in flaps and replanted parts (Maetz et al., 2007). The symbiotic association between Aeromonas and medical leeches has allowed for the use of this invertebrate as a model for digestive tract associations (Graf, 1999; Braschler et al., 2003; Graf et al., 2006). Bacterial virulence factors, such as secretion systems type 2 (T2SS) and type 3 (T3SS) of $A$. veronii, have been studied in the leech model, suggesting that the bacteria use known virulence factors in a manner that allow them to colonize and persist in the leech crop without causing any apparent negative effects (reviewed in Nelson and Graf, 2012). The feasibility of these invertebrate models is based on the low species specificity of the pathogens due to the universality of virulence factors implicated in the infectious process (Froquet et al., 2007).

In the last few years, non-mammalian host models such as fish, particularly zebrafish (Danio rerio), have been used as infection models to study bacterial infections such as those produced by Streptococcus, Salmonella, or Mycobacterium (Neely et al., 2002; van der Sar et al., 2003; Swaim et al., 2006), as well as viral infections produced by rhabdoviruses or Herpes viruses (Burgos et al., 2008; Ludwig et al., 2011; Varela et al., 2014). Adult zebrafish and other fish species, such as rainbow trout and blue gourami, have also been used to study virulence factors of $A$. hydrophila (Yu et al., 2004, 2005; Sha et al., 2005; Canals et al., 2006a, 2007a; Vilches et al., 2007). These fish models offer important advantages. The ease of use and low costs for obtaining large numbers of animals allow for large-scale screening that would be prohibitive in mammals.

In the present work, zebrafish larvae are presented as an alternative animal model to study the virulence factors 
of A. hydrophila using specific mutants of this bacterium. Experimental infections in zebrafish were compared with similar experiments using classical models, such as mice and adult rainbow trout. The great advantage of the zebrafish larvae over other models is that experimental infection by bath immersion mimics the natural route of bacterial infection. Moreover, an injury in the tail also provides a natural portal of entry for the bacteria by mimicking the wounds that are frequently used as a portal to spread infection. The importance of the selection of the right animal model to study virulence factors is discussed.

\section{MATERIALS AND METHODS}

\section{Bacterial Strains, Plasmids, and Growth Conditions}

The bacterial strains and plasmids used in this study are listed in Table 1. Escherichia coli strains were grown on LuriaBertani (LB) Miller broth and LB Miller agar at $37^{\circ} \mathrm{C}$, while $A$. hydrophila strains were grown either in tryptic soy broth (TSB) or agar (TSA) at $30^{\circ} \mathrm{C}$. Spectinomycin $\left(100 \mu \mathrm{g} \cdot \mathrm{mL}^{-1}\right)$,

TABLE 1 | Bacterial strains and plasmids used in this study.

\begin{tabular}{|c|c|c|}
\hline Strain or plasmid & Relevant characteristics & Reference \\
\hline \multicolumn{3}{|l|}{ E. coli strains } \\
\hline $\mathrm{DH} 5 \alpha$ & $\begin{array}{l}\mathrm{F}^{-} \text {end } \mathrm{A} \text { hsdR17 }\left(\mathrm{rK}^{-} \mathrm{mK}^{+}\right) \\
\text {supE44 thi-1 recA1 gyr-A96 } \\
\text { _80lacZM15 }\end{array}$ & Hanahan, 1983 \\
\hline $\mathrm{BL} 21(\lambda \mathrm{D} 3)$ & $\begin{array}{l}\mathrm{F}^{-} \text {ompT hsdS } S_{\mathrm{B}}\left(\mathrm{r}_{\mathrm{B}}^{-} \mathrm{m}_{\mathrm{B}}^{-}\right) \mathrm{gal} \\
d c m(\lambda \mathrm{D} 3)\end{array}$ & Novagen \\
\hline MC1061גpir & $\begin{array}{l}\text { thi thr1 leu6 proA2 his4 argE2 } \\
\text { lacY1 galk2 ara14 xyl5 supE } 44 \lambda \text { pir }\end{array}$ & Canals et al., 2006b \\
\hline \multicolumn{3}{|c|}{ A. hydrophila strains } \\
\hline $\mathrm{AH}-1$ & 011, wild-type & Yu et al., 2004 \\
\hline $\mathrm{AH}-1 \mathrm{Rif}^{\mathrm{R}}$ & Wild-type, rifampicin resistance & Yu et al., 2004 \\
\hline $\mathrm{AH}-1:: a о p B$ & $\begin{array}{l}\mathrm{AH}-1 \text { aopB defined insertion } \\
\text { mutant, } \mathrm{Cm}^{\mathrm{R}}, \mathrm{T}^{-} \mathrm{SS}^{-}\end{array}$ & Yu et al., 2004 \\
\hline $\mathrm{AH}-1 \Delta \mathrm{RmIB}$ & $\begin{array}{l}\mathrm{AH}-1 \mathrm{rm} / \mathrm{B} \text { mutant in frame unable } \\
\text { to produce } 011 \text {-antigen LPS }\end{array}$ & Merino et al., 2015 \\
\hline $\mathrm{AH}-1 \Delta \mathrm{WahD}$ & $\begin{array}{l}\mathrm{AH}-1 \text { wahD mutant in frame unable } \\
\text { to produce O11-antigen LPS and } \\
\text { part of the LPS outer core }\end{array}$ & This work \\
\hline $\mathrm{AH}-1 \Delta$ vapA & $\begin{array}{l}\mathrm{AH}-1 \text { mutant in frame unable to } \\
\text { produce S-layer }\end{array}$ & Merino et al., 2015 \\
\hline AH-1 $\Delta$ FlaB-J & $\begin{array}{l}\mathrm{AH}-1 \text { flaB to } \mathrm{J} \text { deleted mutant in } \\
\text { frame unable to produce polar } \\
\text { flagellum }\end{array}$ & This work \\
\hline $\mathrm{AH}-1:: \operatorname{Mot} \mathrm{X}$ & $\begin{array}{l}\mathrm{AH}-1 \text { motX defined insertion } \\
\text { mutant, } \mathrm{Cm}^{\mathrm{R}} \text {, non-motile }\end{array}$ & This work \\
\hline \multicolumn{3}{|l|}{ Plasmids } \\
\hline pRK2073 & Helper plasmid, $S p^{R}$ & Jimenez et al., 2008 \\
\hline $\mathrm{pDM} 4$ & Suicide plasmid, Sacarose, $\mathrm{Cm}^{\mathrm{R}}$ & Milton et al., 1996 \\
\hline pDM4-WahD & $\begin{array}{l}\text { pDM4 with truncated } \mathrm{AH}-3 \text { wahD, } \\
\text { also pDM } 4 \Delta 5.1\end{array}$ & Jimenez et al., 2008 \\
\hline pDM4-FlaB-J & pDM4 with truncated $\mathrm{AH}-1$ flaB to $\mathrm{J}$ & This work \\
\hline pFS-MotX & $\begin{array}{l}\text { pFS100 with an internal fragment of } \\
\mathrm{AH}-3 \operatorname{mot} X, \mathrm{Km}^{\mathrm{R}} \text {. }\end{array}$ & Canals et al., 2006b \\
\hline
\end{tabular}

rifampicin $\left(100 \mu \mathrm{g} \cdot \mathrm{mL}^{-1}\right)$, chloramphenicol $\left(12.5 \mu \mathrm{g} \cdot \mathrm{mL}^{-1}\right)$, and kanamycin $\left(25 \mu \mathrm{g} \cdot \mathrm{mL}^{-1}\right)$ were added to the different media when required.

\section{Construction of Defined Mutants}

DNA probes from polar flagella region 2 of A. hydrophila AH-3 (Canals et al., 2006b) (actually classified as A. piscicola by BeazHidalgo et al., 2009) allowed for identification of a clone from a cosmid genomic library of $A$. hydrophila AH-1 (Merino et al., 2015). This clone allowed us to use the DNA sequence of complete region 2 (Canals et al., 2006b) of AH-1 and also this DNA sequence for mutant isolation. Mutant $\mathrm{AH}-1 \Delta$ wahD was obtained using plasmid pDM4-wahD generated in strain $\mathrm{AH}$ 3 , as indicated previously (Jimenez et al., 2008). WahD is the glycosyltransferase that adds D-D-Hep to Glc in an $\alpha 1 \rightarrow 6$ linkage (Jimenez et al., 2008).

The chromosomal in-frame flaB-J and wahD deletion mutants A. hydrophila $\mathrm{AH}-1 \Delta \mathrm{FlaB}-\mathrm{J}$ and $\mathrm{AH}-1 \Delta \mathrm{W}$ ahD, respectively, were constructed by allelic exchange as described by Milton et al. (1996). Briefly, upstream (fragment AB) and downstream (fragment CD) fragments of flaB-J were independently amplified using two sets of asymmetric PCRs. Primer pairs A-FlaB (5'-CGG GATCCAACAGTCTG CCAATGGTTC-3'), B-FlaB (5'-CCC ATCCACTAAACTTAAACAGTTAGCCTGAGCCAAAATG-3'), C-FlaJ (5'-TGTTTAAGTTTAGTGGATGGGAGACAACAGCTA GGGGAGTT-3') and D-FlaJ (5'-CGGGATCCAACGTTTCAC AAGCAAGA- $3^{\prime}$ ) amplified DNA fragments of 581 (AB) and 637 (CD) bp for flaB-J in-frame deletion. DNA fragments AB and $\mathrm{CD}$ were annealed and amplified as a single fragment using primers $\mathrm{A}$ and $\mathrm{D}$. The fusion product was purified, and BamHI was digested and ligated into BglII-digested and phosphatase-treated pDM4 vector (Milton et al., 1996); then, it was electroporated into $E$. coli MC1061 ( $\lambda$ pir) and was plated on chloramphenicol plates at $30^{\circ} \mathrm{C}$ to obtain pDM4-FlaB-J. Plasmid pDM4-WahD (formerly pDM4 $\Delta 5.1$ ) was previously obtained (Jimenez et al., 2008). Plasmids pDM4 with mutated genes was transferred into A. hydrophila $\mathrm{AH}-1 \mathrm{Rif}^{\mathrm{R}}$ by triparental mating, using E. coli MC1061 ( $\lambda$ pir) containing the insertion constructs and the mobilizing strain HB101/pRK2073. Transconjugants were selected on plates containing chloramphenicol and rifampicin. PCR analysis confirmed that the vector had integrated correctly into the chromosomal DNA. After sucrose treatment, transconjugants that were rifampicin resistant $\left(\right.$ Rif $\left.{ }^{\mathrm{R}}\right)$ and chloramphenicol sensitive $\left(\mathrm{Cm}^{\mathrm{S}}\right)$ were chosen and confirmed by PCR, obtaining A. hydrophila AH-1 $\Delta$ FlaB-J and AH-1 $\Delta$ WapD mutants.

The insertional defined mutant $\mathrm{AH}-1:$ :motX was constructed using the plasmid construction of strain AH-3 (pSF-MotX) by a single recombination event, leading to the generation of two incomplete copies of motX in the chromosome of the mutant, as previously described (Canals et al., 2006b). Plasmid pSFMotX was isolated, transformed into E. coli MC1061( $\lambda$ pir), and transferred by conjugation from E. coli MC1061 to the A. hydrophila strain AH-1 Rif ${ }^{\mathrm{R}}$, as previously described (Canals et al., 2006b). Km ${ }^{\mathrm{r}}$ Rif $^{\mathrm{r}}$ transconjugants arising from pSFMotX should contain the mobilized plasmid integrated onto the chromosome by homologous recombination between the 
motX and the plasmid, leading to two incomplete copies of the motX (defined insertion mutant). Chromosomal DNA from transconjugants obtained was analyzed by Southern blot hybridization with an appropriate motX DNA probe to obtain the defined insertion AH-1::motX mutant, as previously described (Canals et al., 2006b).

\section{Motility Assays}

Freshly grown bacterial colonies (mutants $\mathrm{AH}-1 \Delta$ flaB-J and $\mathrm{AH}-$ $1:: \operatorname{motX}$ ) were transferred with a sterile toothpick into the center of swim agar ( $1 \%$ tryptone, $0.5 \% \mathrm{NaCl}, 0.25 \%$ agar). The plates were incubated face up for $16-24 \mathrm{~h}$ at $30^{\circ} \mathrm{C}$, and motility was assessed by examining the migration of bacteria through the agar from the center toward the periphery of the plate. Motility was also assessed by light microscopy observations in liquid media.

\section{Transmission Electron Microscopy (TEM)}

Bacterial suspensions (mutants AH-1 $\Delta$ flaB-J and AH-1::motX) were placed on Formvar-coated grids and were negatively stained with a $2 \%$ solution of uranyl acetate at a $\mathrm{pH}$ of 4.1 . The preparations were observed on a Hitachi 600 transmission electron microscope (Hitachi High-Technologies Corp. Tokyo, Japan).

\section{LPS Isolation and SDS-PAGE}

For screening purposes, lipopolysaccharide (LPS) was obtained after proteinase $\mathrm{K}$ digestion of whole cells (Hitchcock and Brown, 1983). LPS samples were separated by SDS-PAGE and were visualized by silver staining, as previously described (Tsai and Frasch, 1982; Hitchcock and Brown, 1983). For largescale isolation, LPS was extracted from dried bacterial cells with aqueous $45 \%$ phenol at $68^{\circ} \mathrm{C}$ by the phenol/water method (Westphal and Jann, 1965). For sugar analysis, a polysaccharide sample $(0.5 \mathrm{mg})$ was hydrolysed with $2 \mathrm{M} \mathrm{CF}_{3} \mathrm{CO}_{3} \mathrm{H}\left(100^{\circ} \mathrm{C}\right.$, $4 \mathrm{~h}$ ), the monosaccharides were conventionally converted into the alditol acetates and analyzed by gas liquid chromatography (GLC) on a Varian 3700 chromatograph (Santa Clara, CA, USA), equipped with a fused-silica gel SPB-5 column using a temperature gradient from $150^{\circ} \mathrm{C}(3 \mathrm{~min})$ to $320^{\circ} \mathrm{C}$ at $5^{\circ} \mathrm{C} \mathrm{min}^{-1}$.

\section{S-layer Purification and Zebrafish Stimulation}

The S-layer sheet material was obtained from the AH-1 $\Delta \mathrm{rmlB}$ mutant (O-antigen negative) as briefly described: cells were grown overnight in $1000 \mathrm{~mL}$ of Luria Broth (LB) with agitation (200 rpm), harvested by centrifugation $(12,000 \times g, 20 \mathrm{~min})$, and washed twice in $20 \mathrm{mM}$ Tris- $\mathrm{HCl}(\mathrm{pH} \mathrm{8.0)}$. They were suspended in $100 \mathrm{~mL}$ of $0.2 \mathrm{M}$ glycine- $\mathrm{HCl}(\mathrm{pH} 2.8)$ and were stirred at $4^{\circ} \mathrm{C}$ for $30 \mathrm{~min}$. The cells were removed by a single centrifugation at $12,000 \times g$ for $20 \mathrm{~min}$. The S-layer sheet material was collected by centrifugation at $40,000 \times g$ for $60 \mathrm{~min}$, suspended in $500 \mathrm{~mL}$ of $20 \mathrm{mM}$ Tris- $\mathrm{HCl}(\mathrm{pH} 8.0)$, and frozen at $-20^{\circ} \mathrm{C}$.

Zebrafish larvae (4 days post fertilization) were microinjected in the Duct of Cuvier with $100 \mathrm{ng}$ of the purified S-layer. The animals were sampled at 3 and $24 \mathrm{~h}$ after stimulation to analyze the gene expression, using the protocol described below in section "Quantitative PCR.”

\section{DNA Manipulations}

General DNA manipulations were performed essentially as previously described (Sambrook et al., 1989). DNA restriction endonucleases, T4 DNA ligase, E. coli DNA polymerase (Klenow fragment), and alkaline phosphatase were used as recommended by Sigma-Aldrich (St. Louis, MO, USA). Double-stranded DNA sequencing was performed using the dideoxy-chain termination method (Sanger et al., 1977) from PCR-amplified DNA fragments with the ABI Prism dye terminator cycle sequencing kit (PerkinElmer, Barcelona, Spain). Oligonucleotides used for genomic DNA amplifications and DNA sequencing were purchased from Sigma-Aldrich (St. Louis, MO, USA). Deduced amino acid sequences were compared with those of DNA translated in all six frames from non-redundant GenBank and EMBL databases, using the BLAST (Altschul et al., 1997) network service at the National Center for Biotechnology Information and the European Biotechnology Information.

\section{Virulence for Fish and Mice}

The virulence of the strains grown at $30^{\circ} \mathrm{C}$ was measured by monitoring their $50 \%$ lethal doses $\left(\mathrm{LD}_{50}\right)$ by the method of Reed and Muench (1938), using different animal models.

Two fish species, rainbow trout (Oncorhynchus mykiss) and zebrafish (Danio rerio), were used to evaluate the virulence of the different mutant strains.

Rainbow trout (15 g mean) were maintained in 20-liter static tanks at $17-18^{\circ} \mathrm{C}$. The fish were injected intraperitoneally with $0.05 \mathrm{~mL}$ of the test samples (approximately $10^{9}$ viable cells), and the mortality was recorded for up to 2 weeks. Three independent experimental infections were conducted. All of the deaths occurred within 2 to 8 days.

Healthy and injured zebrafish larvae (4 dpf) were infected following the protocol described by Saraceni et al. (2016). Injured larvae were obtained by complete transection of the tail fin, using a sapphire blade under an SMZ800 stereomicroscope (Nikon). Groups of ten healthy and injured larvae were distributed into 6-well plates (Falcon) containing $6 \mathrm{~mL}$ of sterile E3 eggs in water. For infection, the bacteria were resuspended in phosphatebuffered saline (PBS) and were added to each well to reach a final concentration of $10^{7}-10^{8} \mathrm{CFU} \cdot \mathrm{mL}^{-1}$ and incubated at $28^{\circ} \mathrm{C}$. The inoculated bacteria were kept in the water during all of the experiments. Control groups were treated with the same volume of PBS. Cumulative mortalities were registered until 120 hpi. All of the experimental infections were performed five times using four biological replicates of 10 larvae each.

Albino Swiss female mice (5-7 weeks old) were injected intraperitoneally with $0.25 \mathrm{ml}$ of the test samples (approximately $5 \times 10^{9}$ viable cells). Mortality was recorded for up to 1 week. Three independent experimental infections were conducted. All of the deaths occurred within 2-5 days.

The protocol estimates several possibilities to sacrifice the animals: when they lose more than $20 \%$ of their weights, when a characteristic pain position is observed (number 3 in our rating), signs of coma, or any self-mutilation. Mortality was considered 
to be caused by the bacterium only if inoculated bacteria were recovered from the studied dead animals. The animals were monitored twice per day and were sacrificed by asphyxiation in a $\mathrm{CO}_{2}$ atmosphere at the end of the experiment or using humane endpoints. No animals involved in the $\mathrm{LD}_{50}$ testing died without human intervention.

\section{Quantitative PCR}

Total larvae RNA was automatically extracted using the Maxwell ${ }^{\circledR} 16$ LEV simply RNA Tissue kit (Promega), according to the manufacturer's instructions. First-strand cDNAs were synthesized using SuperScript II (Life Technologies). The expression of the IL- $1 \beta$ gene was measured by qPCR following the protocol previously described by Pereiro et al. (2015). The elongation factor gene (zEF1) was used as a housekeeping gene to normalize the expression values because it has stable expression that does not change with infection. Fold-change units were calculated by dividing the normalized expression values of the infected larvae by the normalized expression values of the controls. Two independent experiments of 3 biological replicates each were performed.

\section{Bacterial Burden in Infected Zebrafish}

To evaluate the ability of bacterial mutants to induce a stable infection, the evolution of the bacterial burden was analyzed in infected injured zebrafish at 1 and $6 \mathrm{hpi}$. At each time point, four groups of 10 larvae were anesthetized with a lethal dose of MS222 (Sigma-Aldrich), transferred to a tube containing $200 \mu \mathrm{L}$ of 1\% Triton-X100 (BIO-RAD) and mechanically homogenized. Serial dilutions of the homogenates were prepared in PBS and were plated in selective TSA plates. Colony-forming units (CFU) were counted after overnight incubation at $28^{\circ} \mathrm{C}$ in two independent experiments.

\section{In vitro Effects of Mutant Strains}

The effect of bacterial infection was assayed in vitro using primary cultures of the ZF-4 zebrafish cell line. This experiment was conducted three times using three cell cultures each. To evaluate cytotoxicity, bacterial mutants were also added to ZF4 monolayers.

\section{Statistical Analysis}

Kaplan-Meier survival curves for the zebrafish infection experiments were analyzed with the log rank (Mantel-Cox) test. Multiple-comparison ANOVA and Tukey's HSD test were conducted to analyze the evolution of Il-1 $\beta$ gene expression and the bacterial burden. The results are presented as the means \pm standard errors of means (SEMs).

\section{Ethics Statement}

The animal care and experimental infections were performed according to EU guidelines ${ }^{1}$. All of the experiments were performed by specialized technicians from the CSIC and the Faculty of Biology at the University of Barcelona, under the

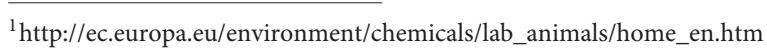

supervision of a veterinarian. All of the protocols were revised and approved by the Committees on Bioethics from the CSIC (151/2014) and by the Ethics Committee of the University of Barcelona (Permit Numbers: 4211 for fish and 4212 for mice).

\section{RESULTS}

\section{Importance of the T3SS in the Pathogenesis of $A$. hydrophila}

The mutant AH-1::aopB lacking a functional T3SS was generated to analyze the implications of this virulence factor in the pathogenesis of A. hydrophila. Sixty-three per cent of the healthy zebrafish larvae infected with the AH-1 wild-type strain survived at the end of the experiment. Mortality started at $24 \mathrm{hpi}$ and increased until 30 hpi. The infection of sibling animals with the mutant AH-1::aopB lacking the T3SS induced significantly lower mortality levels than the wild-type; $80 \%$ of the animals survived to the end of the experiment (Figure 1A). When injured zebrafish larvae were infected, the $\mathrm{AH}-1$ strain induced the death of almost $90 \%$ of the larvae at $120 \mathrm{hpi}$. The rate of survival registered in injured larvae infected with the mutant $\mathrm{AH}-1:: a o p B$ was significantly higher (36\%), and the mortality was delayed until $24 \mathrm{~h}$ (Figure 1B). Similar results were obtained in the five experimental infections conducted.

\section{Evaluation of the O-antigen LPS in the Pathogenesis of $A$. hydrophila}

The lipopolysaccharide mutants used in this study were AH$1 \Delta \mathrm{rmlB}$, which is devoid of the O-antigen LPS with a complete LPS-core, and AH-1 $\Delta$ wahD, which lacks the O-antigen LPS and part of the LPS outer core. Analysis of purified LPS from mutant $\mathrm{AH}-1 \Delta$ wahD by GLC indicated that no D-D-Hep could be found, as well as their increased mobility from wild-type or AH-1 $\triangle$ RmlB mutants in LPS gels, in agreement with the loss of part from the LPS outer core (Figure 2).

Experimental infections of mice and rainbow trout with the mutants $(\mathrm{AH}-1 \Delta \mathrm{rmlB}$ and $\mathrm{AH}-1 \Delta$ wahD) resulted in a significantly increased $\mathrm{LD}_{50}$ compared to the lethal dose using the AH-1 wild-type strain. Infected mice died within 2-5 days postinfection, and the $\mathrm{LD}_{50}$ changed from $10^{6.7}$ using $\mathrm{AH}-1$ wild-type to $>10^{8.0}$ using mutant strains. In rainbow trout, deaths occurred within 2-8 days, and $\mathrm{LD}_{50}$ was also increased in mutant strains (Table 2).

In healthy zebrafish larvae, significantly higher survival rates were obtained in experimental infections with the mutants with changes in the O-antigen and in the LPS core compared to the survival rate obtained after infection with the wildtype bacteria (Figure 3A). The differences in survival rates between the AH-1 wild-type and the mutants were more evident when injured larvae were used for the infections (Figure 3B). In injured larvae, mortality started at $12 \mathrm{hpi}$ regardless of the bacterial strain inoculated, and it resulted in significantly different survival rates according to the LPS modifications. Only $23 \%$ of the fish inoculated with the AH-1 
A

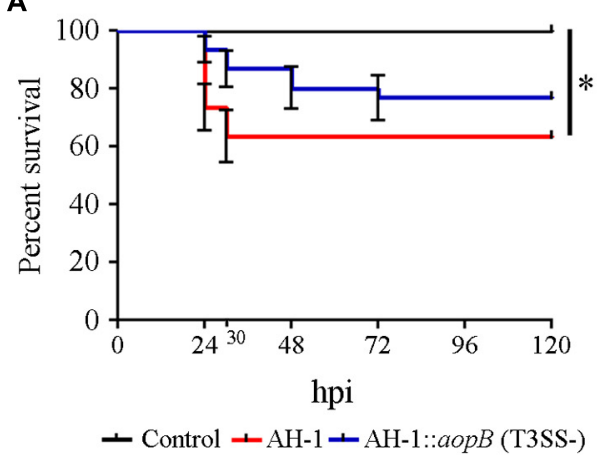

B

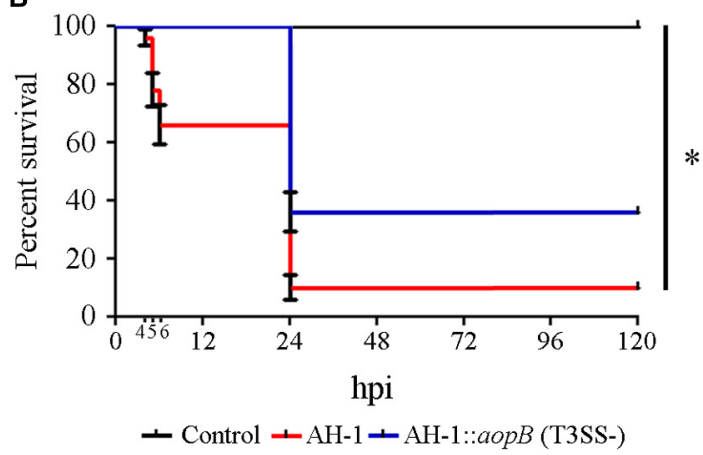

FIGURE 1 | Implications of the T3SS in the pathogenesis of Aeromonas hydrophila. (A) Kaplan-Meier survival curve of healthy larvae after infection with bacterial suspensions. *Significant differences at $P<0.005$. (B) Kaplan-Meier survival curve of injured larvae after infection with bacterial suspensions. *Significant differences at $P<0.0001$. In all cases, the graphs show representative results of five independent experimental infections conducted using four biological replicates of ten larvae each. Healthy and injured larvae were infected with a bacterial suspension (AH-1 wild-type or AH-1::aopB) containing $2 \times 10^{7} \mathrm{CFUs} \cdot \mathrm{mL}^{-1}$ and $5 \times 10^{7} \mathrm{CFUs} \cdot \mathrm{mL}^{-1}$, respectively.

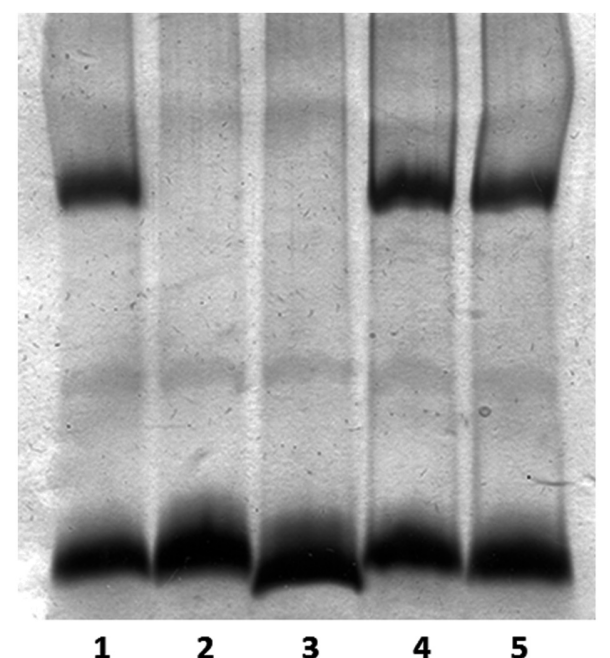

FIGURE 2 | Lipopolysaccharide (LPS) analyzed by SDS-Tricine gel and silver stained for $A$. hydrophila strains: AH-1 wild-type (lane 1), AH-1 $\Delta$ rmIB mutant (lane 2), AH-1 $\Delta$ wahD mutant (lane 3), AH-1 $\Delta$ rmIB mutant complemented with pBAD-rmIB (lane 4), and AH-1 $\Delta$ WahD mutant complemented with pBAD-wahA (lane 5).

wild-type survived. Modifications in the LPS induced significant increases in the survival rates at the end of the experiment. Forty-six percent of the fish inoculated with the mutant $\mathrm{AH}-1 \Delta$ wahD lacking the LPS-core and completely lacking the O-antigen survived, while $70 \%$ of fish infected with the mutant lacking $\mathrm{O}$-antigen $(\mathrm{AH}-1 \Delta \mathrm{RmlB})$ were alive at $144 \mathrm{hpi}$ (Figure 3B).

\section{Importance of the S-layer in the Pathogenesis of $A$. hydrophila}

Results obtained in experimental infections of mice and rainbow trout with the mutant $\mathrm{AH}-1 \Delta \mathrm{vapA}$ (S-layer negative) showed
TABLE 2 | LD $_{50}$ for rainbow trout and mice of Aeromonas hydrophila AH-1 and its mutants upon intraperitoneal injection of strains grown in TSB at $20^{\circ} \mathrm{C}$ to infect fish and at $37^{\circ} \mathrm{C}$ to infect mice.

\begin{tabular}{|c|c|c|}
\hline Strain & Rainbow trout & Mice \\
\hline $\mathrm{AH}-1$ wild-type & $10^{4.5}$ & $10^{6.7}$ \\
\hline $\mathrm{AH}-1 \Delta$ rmIB $\left(\mathrm{O}\right.$-antigen $\left.\mathrm{LPS}^{-}\right)$ & $10^{6.1}$ & $>10^{8.0}$ \\
\hline $\mathrm{AH}-1 \Delta$ wahD $\left(\mathrm{O}\right.$-antigen and outer-core $\left.\mathrm{LPS}^{-}\right)$ & $10^{6.8}$ & $>10^{8.0}$ \\
\hline $\mathrm{AH}-1 \Delta{\text { vapA }\left(\mathrm{S}-\text { layer }^{-}\right)}^{-}$ & $10^{4.6}$ & $10^{6.7}$ \\
\hline AH-1 $\Delta$ flaB-J (polar flagellum ${ }^{-}$) & $10^{4.4}$ & $10^{6.8}$ \\
\hline $\mathrm{AH}-1:: \operatorname{motX}\left(\right.$ motility $\left.^{-}\right)$ & $10^{4.5}$ & $10^{6.6}$ \\
\hline
\end{tabular}

The values are the averages from three independent experiments, and the maximum deviation was always $<10^{0.3}$.

that the mutant strain was as pathogenic as the wild-type. In both animal models, the $\mathrm{LD}_{50}$ obtained after ip injection was not different between the wild-type and mutant strains. The $\mathrm{LD}_{50}$ for mice and trout were $10^{6.7}$ and $10^{4.6}$, respectively (Table 2 ). In healthy zebrafish larvae, AH-1 $\Delta$ vapA had low pathogenicity and produced less than $10 \%$ of the cumulative mortality. Ninety-three percent of infected fish survived at the end of the experiment. This percentage of survival was significantly higher than that registered in fish infected with the $\mathrm{AH}-1$ wild-type strain, in which $66 \%$ of the fish survived the infection (Figure 4A). However, when injured larvae were infected, the mutant AH$1 \Delta$ vapA produced the same cumulative mortality levels as the $\mathrm{AH}-1$ strain. The mortality started as soon as $8 \mathrm{hpi}$ and reached the maximum value (up to $80 \%$ ) at $24 \mathrm{hpi}$. Only $13 \%$ of the fish survived the bacterial infection (Figure 4B). The proinflammatory activity of the purified S-layer was assayed by qPCR to measure the Il-1 $\beta$ gene expression. The treatment of fish with the purified S-layer induced a significant increase in Il-1 $\beta$ gene expression at $3 \mathrm{hpi}$, reaching fold changes as much as six times greater than the control group. The expression level registered at $24 \mathrm{~h}$ was significantly lower than that registered at $3 \mathrm{~h}$, but no significant differences were observed between the control and stimulated fish at this time (Figure 4C). 

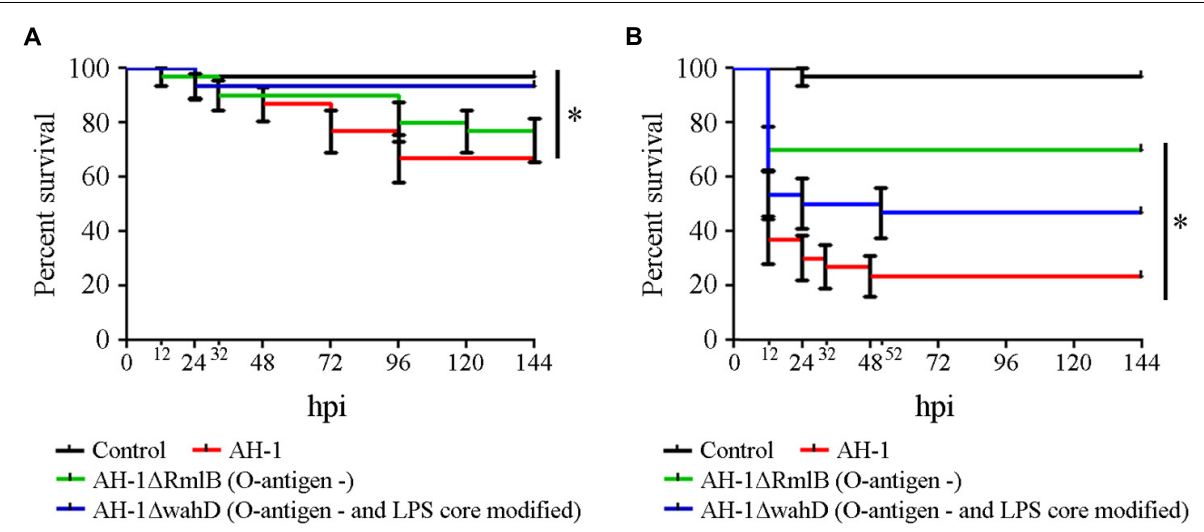

FIGURE 3 | Implications of the O-antigen in the pathogenesis of $\boldsymbol{A}$. hydrophila. (A) Kaplan-Meier survival curve of healthy larvae infected with A. hydrophila $\mathrm{AH}-1$ wild-type and the mutants $\mathrm{AH}-1 \Delta \mathrm{RmIB}(\mathrm{O}$-antigen negative) and $\mathrm{AH}-1 \Delta$ wahD $(\mathrm{O}$-antigen negative and altered part of the $\mathrm{LPS}$ outer-core). $*$ Significant differences at $P=0.0062$. (B) Kaplan-Meier survival curve of injured larvae after infection with the same bacterial suspensions. *Significant differences at $P<0.0001$.

A

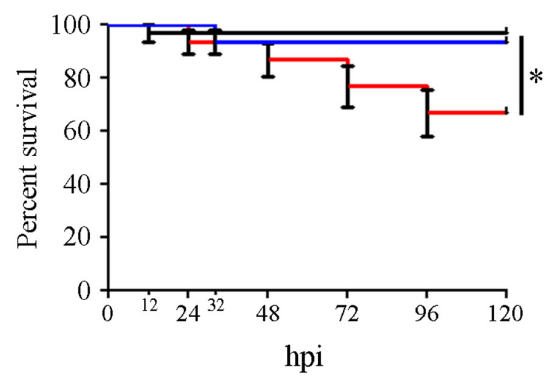

- Control L- AH-1 - $\mathrm{AH}-1 \Delta \mathrm{vapA}(\mathrm{S}-1$ layer - $)$
B

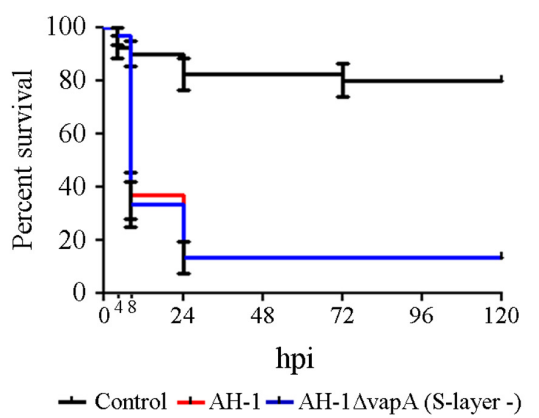

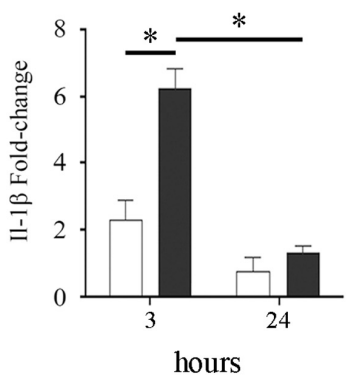

$\square$ Control $\square$ S-layer

FIGURE 4 | Implications of the S-layer in the pathogenesis of $\boldsymbol{A}$. hydrophila. (A) Kaplan-Meier survival curve of healthy (A) and injured (B) larvae infected with A. hydrophila AH-1 wild-type and the mutant $\mathrm{AH}-1 \Delta$ vapA (S-layer negative). *Significant differences at $P=0.002$. (C) Effects of microinjection of the purified AH-1 S-layer (100 ng) on the expression of II- $1 \beta$ at 3 and 24 h post-injection. * Significant differences at $p<0.001$.

\section{Implications of the Motility and Polar Flagella in the Pathogenesis of \\ A. hydrophila}

To analyze the implications of the bacterial motility and polar flagella in the pathogenesis of A. hydrophila, two mutants were generated. The AH-1 $\Delta$ flaB-J mutant lacked a polar flagellum and was not able to swim, and the AH-1::motX mutant was non-motile but was able to produce a polar flagellum (Figure 5).

When these mutants were injected into rainbow trout or mice, no differences in the $\mathrm{LD}_{50}$ of the mutants $\mathrm{AH}-1 \Delta$ flaB-J or AH-1::motX, compared to wild-type strain, could be observed (Table 2). Surprisingly, when zebrafish were infected with the mutants $\mathrm{AH}-1 \Delta$ flaB-J or AH-1::motX, no mortality was registered in either healthy (data not shown) or injured larvae (Figure 6A).

After infection, the bacterial load in fish significantly increased from 1 to $6 \mathrm{hpi}$ in the fish infected with the AH-1 wild-type bacteria and those infected only with the mutant AH-1::motX (no motility). The bacterial concentration of mutant AH- $1 \Delta$ flaB-J, which was also not motile because it lacked the polar flagellum, did not increase during the experiment and was maintained at a low level (Figure 6B).

\section{In vitro Effects of Mutant Strains}

No differences in cytotoxicity were observed among the AH-1 wild-type and most of the mutants. Only AH-1::aopB, lacking the T3SS, did not induce cytotoxicity in ZF-4 cell culture (data not shown).

\section{DISCUSSION}

One of the most important issues in the study of the virulence factors of pathogenic bacteria is the selection of the experimental model, especially when the obtained results are intended to be extrapolated from the selected model to humans. In the present work, the infection of zebrafish larvae by bath immersion was proposed as an alternative model for the study of the virulence factors of $A$. hydrophila. The great advantage of zebrafish larvae over other models is that experimental infection by bath immersion mimics the natural route of infection. Moreover, 


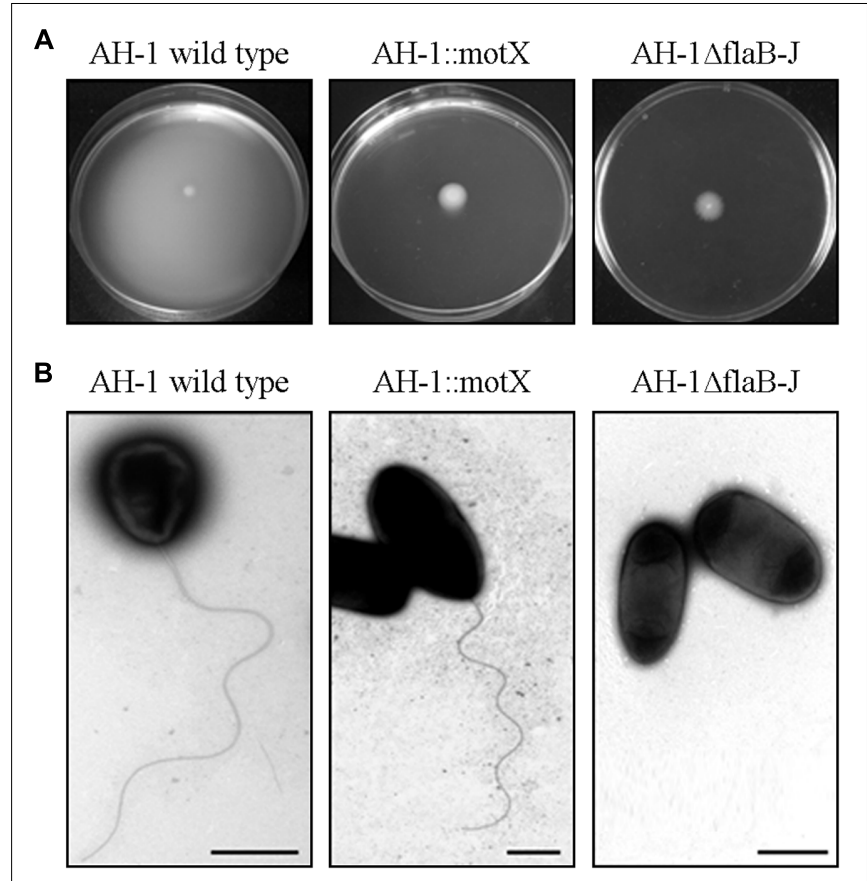

FIGURE 5 | (A) Motility swimming in semisolid agar plates of the strain $\mathrm{AH}-1$ wild-type, $\mathrm{AH}-1:: \operatorname{motX}$ mutant (no motility), and $\mathrm{AH}-1 \Delta$ flaB-J mutant (polar flagella negative). (B) Transmission electron microscopy (TEM) of $A$. hydrophila strains. Bacteria were gently placed onto Formvar-coated copper grids and were negatively stained using a $2 \%$ solution of uranyl acetate. Bar $=1 \mu \mathrm{m}$.

injury to the tail also provides a natural portal of entry for the bacteria, mimicking wounds that are frequently used as a portal to spread infection (Janda and Abbott, 2010). Classical experimental intraperitoneal infections in mice and rainbow trout were compared with bath-infected zebrafish larvae using A. hydrophila containing several modifications in the virulence factors.

First, the feasibility of the zebrafish larvae infection model to study the virulence factors of $A$. hydrophila was evaluated in experimental infections using the type III secretion system (TTSS) AH-1::aopB mutant strain, which was already used in mice and fish (Yu et al., 2004; Sha et al., 2005). The disruption of the T3SS by mutations induced a decrease in bacterial virulence (Vilches et al., 2004, 2008, 2012). The AH-1::aopB mutant was less virulent than the wild-type strain when inoculated by bath into zebrafish larvae. This result was in agreement with previous infections in mice and blue gourami, describing lower virulence after intraperitoneal infection with the same mutant strain (Yu et al., 2004; Sha et al., 2005). Interestingly, when the infection was conducted in injured zebrafish larvae, a $48 \mathrm{~h}$ delay in mortality was registered. This delay in mortality was not previously observed using vertebrate models (mice and adult fish), but it was described in experimental infections using invertebrate models: the insect $T$. molitor and the crustacean P. leniusculus (Noonin et al., 2010). Therefore, when the implications of the T3SS in the virulence of $A$. hydrophila were analyzed, the injured zebrafish larvae model could produce not only the variations previously described in other vertebrate models but also slight differences in mortality kinetics only observed using invertebrate models.

The implications of the surface-associated S-layer in the pathogenesis of $A$. hydrophila were also evaluated in mice and rainbow trout and were compared to zebrafish larvae using the mutant AH-1 $\Delta$ vapA, which lacks the gene coding for the surface layer protein (Merino et al., 2015). This surface structure is an essential virulence factor of $A$. hydrophila, especially in strains highly virulent to mice and fish (Mittal et al., 1980; Dooley and Trust, 1988; Murray et al., 1988; Noonan and Trust, 1997; Esteve et al., 2004). When the mutant AH-1 $\Delta$ vapA was intraperitoneally injected into trout and mice and was inoculated into injured zebrafish larvae, offering the bacteria an alternative portal of entry to the body, this mutant was as pathogenic as the wild-type strain. It was described that a double mutant (S-layer and metalloproteases) and a triple mutant (S-layer, metalloproteases, serine protease) were less pathogenic than the wild-type when infecting blue gourami (Yu et al., 2005), suggesting that additional mutations outside of the S-layer were needed to induce a decrease
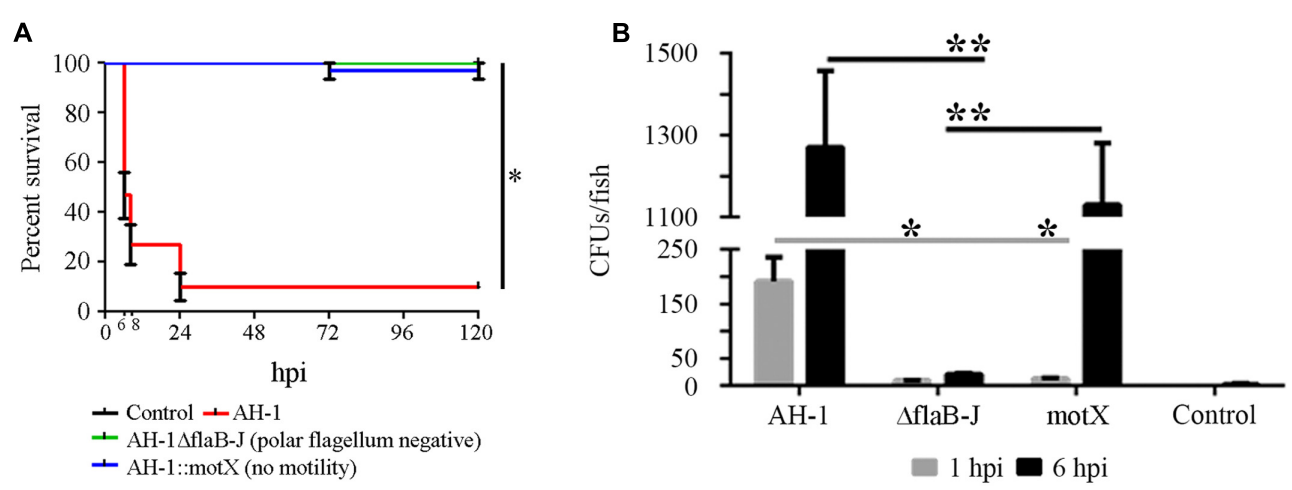

FIGURE 6 | Implication of the polar flagellum and the motility in the pathogenesis of $\boldsymbol{A}$. hydrophila. (A) Kaplan-Meier survival curve of injured larvae infected with $A$. hydrophila $\mathrm{AH}-1$ wild-type and the mutants $\mathrm{AH}-1 \Delta$ flaB-J (polar flagellum negative) and $\mathrm{AH}-1:$ motX (no motility). $*$ Significant differences at $P<0.0001$.

(B) Bacterial burden of infected larvae at 1 and 6 hpi. Mean \pm SEM of two independent experiments are presented $\left(n=10\right.$ larvae per group). ${ }^{*} p<0.05, * * p<0.01$. 
in virulence. Surprisingly when healthy zebrafish larvae were infected, the mutant strain produced less mortality than the wild-type. This result suggested that the S-layer was not totally necessary to the bacteria once it was inside the host, but it contributed to the inflammatory response because it was observed with high expression levels of IL-1 $\beta$. The implications of the S-layer proteins in the induction of proinflammatory cytokines, such as IL-12p70, TNF $\alpha$, and IL-1 $\beta$, have already been described in dendritic and T cells infected with the S-layer mutant Lactobacillus acidophilus NCFM (Konstantinov et al., 2008).

The sensitivity of the zebrafish larvae model to minor variations in the pathogenicity of mutant stains when analyzing the function of the different virulence factors was also evidenced in the analysis of the LPS structures. In the present work, two LPS-mutant strains were used: $\mathrm{AH}-1 \Delta \mathrm{rmlB}$, which is devoid of the O-antigen LPS with a complete LPS core (Merino et al., 2015), and $\mathrm{AH}-1 \Delta$ wahD, which lacks the O-antigen LPS and part of the LPS outer core. To our knowledge, this study is the first report describing the pathogenicity of a mutant AH1 strain including residue modifications from the LPS outer core. Regardless of the animal model (mice, trout or zebrafish) and the route of infection (ip injection and bath), the experimental infections with both AH1 mutant strains lacking the O-antigen LPS and the outer core LPS resulted in decreased cumulative mortality. It has been well described that modifications in the O-antigen LPS generated by physical environmental conditions (osmolarity and temperature; Aguilar et al., 1997) or the introduction of specific mutations in galU, galE, and gne of the A. hydrophila AH3 O:34 (Canals et al., 2006a, 2007a; Vilches et al., 2007) resulted in a decrease in virulence (Merino et al., 2015). Interestingly, when injured zebrafish larvae were infected, differences in mortality were observed between the mutants $\mathrm{AH}-1 \Delta \mathrm{rmlB}$ (lacking of the O-antigen LPS) and AH- $1 \Delta$ wahD (which lacks the O-antigen LPS and part of the LPS outer-core), which were not previously observed in mice and trout after ip infection. This result suggests that residues from the LPS outer core must be important for virulence. Once again, the injured zebrafish larvae infection model seemed to be more feasible for the study of this virulence factor because ip injection of mice and trout did not enable the detection of slight changes in the bacterial virulence induced by changes in the LPS outer core.

However, the greatest differences depending on the animal model were obtained in the analysis of the polar flagella and the bacterial motility. The A. hydrophila strain AH-1 is motile in liquid medium (swimming) through the expression of a polar flagellum, and it produces lateral flagella when grown in semisolid or solid media, being able to swarm. Two mutants were isolated and used: AH-1 $\Delta$ FlaB-J, a non-polar flagellated mutant unable to swim, and $\mathrm{AH}-1: \mathrm{motX}$, which is non-motile but able to produce polar flagella.

A clear effect of motility on the pathogenesis of $A$. hydrophila was observed. AH-1 $\Delta$ FlaB-J and AH-1::motX were as pathogenic as the wild-type strain when injected into mice and rainbow trout. In these models, the bacteria reached the animal body without using the mutated structures and were able to progress inside the animal, like the wild-type. However, when zebrafish larvae were used, no mortality was registered in either $\mathrm{AH}$ $1 \Delta$ FlaB-J- or AH-1::motX-infected fish. The bacterial burden of the mutant strains was evaluated to determine the stable presence of bacteria in the fish. Interestingly, the mutant AH- $1 \Delta$ flaB-J lacking the polar flagellum was not able to replicate inside the fish, while the non-motile mutant strain (AH-1::motX) had the polar flagellum but could not use it. These results suggested that the polar flagellum could be involved not only in motility and adherence but also in bacterial virulence. The lack of flagella or the loss in motility affects the pathogenicity of the bacteria, very likely due to a decrease in adherence to the fish surface to proceed with the infection. This observation was demonstrated using similar A. hydrophila mutants (without polar flagella and motility), showing a reduced ability to attach to human epithelial cells and to form biofilms (Gryllos et al., 2001; Canals et al., 2006b, 2007b). Moreover, A. hydrophila polar flagellum mutants had less survival and adherence to eel macrophages (Qin et al., 2014).

TLR5 (Toll-like receptor 5) recognizes flagellin by its dominion D1 triggering the activation of proinflammatory and immune genes through the NF- $\mathrm{B}$ (nuclear factor-kappa B) and MAPK (mitogen-activated protein kinase) routes (Hayashi et al., 2001). The AH-1::motX mutant cannot move the flagellum, which can result in low fragmentation of this structure, thus avoiding recognition of the flagellum D0-D1 domains by TLR5. This partial activation of TLR 5 could induce low activation of the immune response meditated by this receptor.

The analysis of all of the virulence factors was also conducted in cell culture using ZF-4 cells. No differences in cytotoxicity were observed between mutants and the wild-type strain. Only AH-1::aopB lacking the T3SS was unable to induce cytotoxicity, in agreement with previous publications using EPC cells, RAW 264.7 murine macrophages and HT-29 human colonic epithelial cells (Yu et al., 2004; Sha et al., 2005).

This study demonstrates that zebrafish larvae can be used as a simple host model to assess the virulence factors of A. hydrophila. This animal model reveals many more differences in pathogenicity than the in vitro experiments and enables the detection of slight variations in pathogenesis not previously observed using the classic ip injection of mice or fish.

\section{AUTHOR CONTRIBUTIONS}

$\mathrm{BN}, \mathrm{PS}, \mathrm{AR}, \mathrm{SM}, \mathrm{JT}$, and AF contributed to the conception of the work. PS, AR, and SM acquired and analyzed the data for the work. PS, AR, BN, SM, JT, and AF interpreted the data. PS, $\mathrm{AR}$, and $\mathrm{BN}$ drafted the work. AF, AR, JT, SM, and BN revised the article critically for important intellectual content. PS, AR, $\mathrm{SM}, \mathrm{AF}, \mathrm{JT}$, and BN approved the final version of the article to be published.

\section{ACKNOWLEDGMENTS}

This work was partially funded by the projects CSD2007-00002 "Aquagenomics", AGL2014-51773-C3, 201230E057 (CSIC) and BIO2013-47198-P, from the Spanish Ministerio de Economía 
y Competitividad, from Generalitat de Catalunya (Centre de Referència en Biotecnologia), and from ITN 289209 (FISHFORPHARMA) (EU). PR Saraceni received a Marie

\section{REFERENCES}

Aguilar, A., Merino, S., Rubires, X., and Tomas, J. M. (1997). Influence of osmolarity on lipopolysaccharides and virulence of Aeromonas hydrophila serotype O:34 strains grown at 37 degrees C. Infect. Immun. 65, 1245-1250.

Altschul, S. F., Madden, T. L., Schäffer, A. A., Zhang, J., Zhang, Z., Miller, W., et al. (1997). Gapped BLAST and PSI-BLAST: a new generation of protein database search programs. Nucleic Acids Res. 25, 3389-3402. doi: 10.1093/nar/25.17.3389

Beaz-Hidalgo, R., Alperi, A., Figueras, M. J., and Romalde, J. L. (2009). Aeromonas piscicola sp. nov., isolated from diseased fish. Syst. Appl. Microbiol. 32, 471-479. doi: 10.1016/j.syapm.2009.06.004

Bickel, K. D., Lineaweaver, W. C., Follansbee, S., Feibel, R., Jackson, R., and Buncke, H. J. (1994). Intestinal flora of the medicinal leech Hirudinaria manillensis. J. Reconstr. Microsurg. 10, 83-85. doi: 10.1055/s-2007-1006575

Braschler, T. R., Merino, S., Tomas, J. M., and Graf, J. (2003). Complement resistance is essential for colonization of the digestive tract of Hirudo medicinalis by Aeromonas Strains. Appl. Environ. Microbiol. 69, 4268-4271. doi: 10.1128/AEM.69.7.4268-4271.2003

Burgos, J. S., Ripoll-Gomez, J., Alfaro, J. M., Sastre, I., and Valdivieso, F. (2008). Zebrafish as a new model for herpes simplex virus type 1 infection. Zebrafish 5, 323-333. doi: 10.1089/zeb.2008.0552

Canals, R., Jiménez, N., Vilches, S., Regué, M., Merino, S., and Tomás, J. M. (2006a). The UDP N-acetylgalactosamine 4-epimerase gene is essential for mesophilic Aeromonas hydrophila serotype O34 virulence. Infect. Immun. 74, 537-548. doi: 10.1128/IAI.74.1.537-548.2006

Canals, R., Jiménez, N., Vilches, S., Regué, M., Merino, S., and Tomás, J. M. (2007a). Role of Gne and GalE in the virulence of Aeromonas hydrophila serotype O34. J. Bacteriol. 189, 540-550. doi: 10.1128/JB.01260-06

Canals, R., Ramirez, S., Vilches, S., Horsburgh, G., Shaw, J. G., Tomás, J. M., et al. (2006b). Polar flagellum biogenesis in Aeromonas hydrophila. J. Bacteriol. 188, 542-555. doi: 10.1128/JB.188.8.3166.2006

Canals, R., Vilches, S., Wilhelms, M., Shaw, J. G., Merino, S., and Tomás, J. M. (2007b). Non-structural flagella genes affecting both polar and lateral flagellamediated motility in Aeromonas hydrophila. Microbiology 153, 1165-1175. doi: 10.1099/mic.0.2006/000687-0

Cantas, L., Sørby, J. R., Aleström, P., and Sørum, H. (2012). Culturable gut microbiota diversity in zebrafish. Zebrafish 9, 26-37. doi: 10.1089/zeb.2011.0712

Chen, P. L., Wu, C. J., Tsai, P. J., Tang, H. J., Chuang, Y. C., Lee, N. Y., et al. (2014). Virulence diversity among bacteremic Aeromonas isolates: ex vivo, animal, and clinical evidences. PLoS ONE 9:e111213. doi: 10.1371/journal.pone.0111213

Chopra, A. K., and Houston, C. W. (1999). Enterotoxins in Aeromonasassociated gastroenteritis. Microbes Infect. 1, 1129-1137. doi: 10.1016/S12864579(99)00202-6

Cipriano, R. C., Bullock, G. L., and Pyle, S. W. (1984). Aeromonas hydrophila and Motile Aeromonad Septicemias of Fish. Paper No. 134. Washington, DC: US Fish $\&$ Wildlife Publications.

Dooley, J. S., and Trust, T. J. (1988). Surface protein composition of Aeromonas hydrophila strains virulent for fish: identification of a surface array protein. J. Bacteriol. 170, 499-506.

Esterabadi, A. H., Entessar, F., and Khan, M. A. (1973). Isolation and identification of Aeromonas hydrophila from an outbreak of haemorrhagic septicemia in snakes. Can. J. Comp. Med. 37, 418-420.

Esteve, C., Alcaide, E., Canals, R., Merino, S., Blasco, D., Figueras, M. J., et al. (2004). Pathogenic Aeromonas hydrophila serogroup O:14 and O:81 strains with an S layer. Appl. Environ. Microbiol. 70, 5898-5904. doi: 10.1128/AEM.70.10.5898-5904.2004

Fadl, A. A., Galindo, C. L., Sha, J., Zhang, F., Garner, H. R., Wang, H. Q., et al. (2007). Global transcriptional responses of wild-type Aeromonas hydrophila and its virulence-deficient mutant in a murine model of infection. Microb. Pathog. 42, 193-203. doi: 10.1016/j.micpath.2007.02.002

Froquet, R., Cherix, N., Burr, S., Frey, J., Vilches, S., Tomas, J. M., et al. (2007). An alternative host model to measure Aeromonas virulence. Appl. Environ. Microbiol. 73, 5657-5659. doi: 10.1128/AEM.00908-07
Curie Fellowship from the EU. We thank Maite Polo for her technical assistance and the Servicios Científico-Técnicos from the University of Barcelona.

Fulton, M. (1965). The bacterium Aeromonas hydriphila from lizards of the genus Anolis in Puerto Rico. Carib. Jour. Sci. 2, 105-107.

Garvis, S., Munder, A., Ball, G., De, B. S., Wiehlmann, L., Ewbank, J. J., et al. (2009). Caenorhabditis elegans semi-automated liquid screen reveals a specialized role for the chemotaxis gene cheB2 in Pseudomonas aeruginosa virulence. PLoS Pathog. 5:e1000540. doi: 10.1371/journal.ppat.1000540

Glunder, G., and Siegmann, O. (1989). Occurrence of Aeromonas hydrophila in wild birds. Avian Pathol. 18, 685-695. doi: 10.1080/03079458908418642

Goy, G., Thomas, V., Rimann, K., Jaton, K., Prod'hom, G., and Greub, G. (2007). The Neff strain of Acanthamoeba castellanii, a tool for testing the virulence of Mycobacterium kansasii. Res. Microbiol. 158, 393-397. doi: 10.1016/j.resmic.2007.01.003

Graf, J. (1999). The symbiosis of Aeromonas veronii bv. sobria and Hirudo medicinalis, the medicinal leech: a novel model for digestive tract associations. Infect. Immun. 67, 1-7.

Graf, J., Kikuchi, Y., and Rio, R. V. M. (2006). Leeches and their microbiota: naturally simple symbiosis models. Trends Microbiol. 14, 365-371. doi: 10.1016/j.tim.2006.06.009

Gray, S. J. (1984). Aeromonas hydrophila in livestock: incidence, biochemical characteristics and antibiotic susceptibility. J. Hyg. 92, 365-375. doi: $10.1017 /$ S0022172400064585

Gryllos, I., Shaw, J. G., Gavín, R., Merino, S., and Tomás, J. M. (2001). Role of flm locus in mesophilic Aeromonas species adherence. Infect. Immun. 69, 65-74. doi: 10.1128/IAI.69.1.65-74.2001

Hanahan, D. (1983). Studies on transformation of Escherichia coli with plasmids. J. Mol. Biol. 166, 557-580. doi: 10.1016/S0022-2836(83)80284-8

Hayashi, F., Smith, K. D., Ozinsky, A., Hawn, T. R., Yi, E. C., Goodlett, D. R., et al. (2001). The innate immune response to bacterial flagellin is mediated by toll like receptor 5. Nature 410, 1099-1103. doi: 10.1038/35074106

Hill, A. W., Newman, S. J., Craig, L., Carter, C., Czarra, J., and Brown, J. P. (2010). Diagnosis of Aeromonas hydrophila, Mycobacterium species, and Batrachochytrium dendrobatidis in an African Clawed Frog (Xenopus laevis). J. Am. Assoc. Lab. Anim. Sci. 49, 215-220.

Hitchcock, P. J., and Brown, T. M. (1983). Morphological heterogeneity among Salmonella lipopolysaccharide chemotypes in silver-stained polyacrylamide gels. J. Bacteriol. 154, 269-277.

Janda, J. M., and Abbott, S. L. (2010). The genus Aeromonas: taxonomy, pathogenicity, and infection. Clin. Microbiol. Rev. 23, 35-73. doi: 10.1128/CMR.00039-09

Jimenez, N., Canals, R., Lacasta, A., Kondakova, A. N., Lindner, B., Knirel, Y. A., et al. (2008). Molecular analysis of three Aeromonas hydrophila AH-3 (serotype O34) lipopolysaccharide core biosynthesis gene clusters. J. Bacteriol. 190, 31763184. doi: 10.1128/JB.01874-07

Jiravanichpaisal, P., Roos, S., Edsman, L., Liu, H., and Söderhäll, K. (2009). A highly virulent pathogen, Aeromonas hydrophila, from the freshwater crayfish Pacifastacus leniusculus. J. Invertebr. Pathol. 101, 56-66. doi: 10.1016/j.jip.2009.02.002

Konstantinov, S. R., Smidt, H., de Vos, W. M., Bruijns, S. C., Singh, S. K., Valence, F., et al. (2008). S layer protein A of Lactobacillus acidophilus NCFM regulates immature dendritic cell and T cell functions. Proc. Natl. Acad. Sci. U.S.A. 105, 19474-19479. doi: 10.1073/pnas.0810305105

Kurz, C. L., and Ewbank, J. J. (2007). Infection in a dish: high-throughput analyses of bacterial pathogenesis. Curr. Opin. Microbiol. 10, 10-16. doi: 10.1016/j.mib.2006.12.001

Ludwig, M., Palha, N., Torhy, C., Briolat, V., Colucci-Guyon, E., Brémont, M., et al. (2011). Whole-body analysis of a viral infection: vascular endothelium is a primary target of infectious hematopoietic necrosis virus in zebrafish larvae. PLoS Pathog. 7:e1001269. doi: 10.1371/journal.ppat. 1001269

Lutter, E. I., Faria, M. M., Rabin, H. R., and Storey, D. G. (2008). Pseudomonas aeruginosa cystic fibrosis isolates from individual patients demonstrate a range of levels of lethality in two Drosophila melanogaster infection models. Infect. Immun. 76, 1877-1888. doi: 10.1128/IAI.01165-07 
Maetz, B., Abbou, R., Andreoletti, J. B., and Bruant-Rodier, C. (2007). Infections following the application of leeches: two case reports and review of the literature. J. Med. Case Rep. 6:364. doi: 10.1186/1752-1947-6-364

Merino, S., Canals, R., Knirel, Y. A., and Tomás, J. M. (2015). Molecular and chemical analysis of the lipopolysaccharide from Aeromonas hydrophila strain AH-1 (serotype O11). Mar. Drugs 13, 2233-2249. doi: 10.3390/md130 42233

Merino, S., Rubires, X., Aguilar, A., and Tomás, J. M. (1997). The role of flagella and motility in the adherence and invasion to fish cell lines by Aeromonas hydrophila serogroup O:34 strains. FEMS Microbiol. Lett. 151, 213-217. doi: 10.1111/j.1574-6968.1997.tb12572.x

Milton, D. L., O’Toole, R., Horstedt, P., and Wolf-Watz, H. (1996). Flagellin A is essential for the virulence of Vibrio anguillarum. J. Bacteriol. 178, 1310-1319.

Mittal, K. R., Lalonde, G., Leblanc, D., Olivier, G., and Laflier, R. (1980). Aeromonas hydrophila in rainbow trout: relation between virulence and surface characteristics. Can. J. Microbiol. 26, 1501-1503. doi: 10.1139/m80-248

Murray, R. G., Dooley, J. S., Whippey, P. W., and Trust, T. J. (1988). Structure of an S layer on a pathogenic strain of Aeromonas hydrophila. J. Bacteriol. 170, 2625-2630.

Neely, M. N., Pfeifer, J. D., and Caparon, M. (2002). Streptococcus-zebrafish model of bacterial pathogenesis. Infect. Immun. 70, 3904-3914. doi: 10.1128/IAI.70.7.3904-3914.2002

Nelson, M. C., and Graf, J. (2012). Bacterial symbioses of the medicinal leech Hirudo verbana. Gut Microbes 3, 322-331. doi: 10.4161/gmic.20227

Noonan, B., and Trust, T. (1997). The synthesis, secretion and role in virulence of the paracrystalline surface protein layers of Aeromonas salmonicida and A. hydrophila. FEMS Microbiol. Lett. 154, 1-7. doi: 10.1111/j.15746968.1997.tb12616.x

Noonin, C., Jiravanichpaisal, P., Söderhäll, I., Merino, S., Tomás, J. M., and Söderhäll, K. (2010). Melanization and pathogenicity in Tenebrio molitor and Pacifastacus leniusculus by Aeromonas hydrophila. PLoS ONE 5:e15728. doi: 10.1371/journal.pone.0015728

O'Callaghan, D., and Vergunst, A. (2010). Non-mammalian animal models to study infectious disease: worms or fly fishing? Curr. Opin. Microbiol. 13, 79-85. doi: $10.1016 /$ j.mib.2009.12.005

Parker, J. L., and Shaw, J. G. (2011). Aeromonas spp. clinical microbiology and disease. J. Infect. 62, 109-118. doi: 10.1016/j.jinf.2010.12.003

Pereiro, P., Varela, M., Diaz-Rosales, P., Romero, A., Dios, S., Figueras, A., et al. (2015). Zebrafish Nk-lysins: first insights about their cellular and functional diversification. Dev. Comp. Immunol. 51, 148-159. doi: 10.1016/j.dci.2015.03.009

Qin, Y., Lin, G., Chen, W., Huang, B., Huang, W., and Yan, Q. (2014). Flagellar motility contributes to the invasion and survival of Aeromonas hydrophila in Anguilla japonica macrophages. Fish Shellfish Immunol. 39, 273-279. doi: 10.1016/j.fsi.2014.05.016

Ramarao, N., Nielsen-Leroux, C., and Lereclus, D. (2012). The insect Galleria mellonella as a powerful infection model to investigate bacterial pathogenesis. J. Vis. Exp. 70:e4392. doi: 10.3791/4392

Reed, L. J., and Muench, H. (1938). A simple method of estimating fifty percent end points. Am. J. Hyg. 27, 493-497.

Reyes-Becerril, M., López-Medina, T., Ascencio-Valle, F., and Esteban, M. Á. (2011). Immune response of gilthead seabream (Sparus aurata) following experimental infection with Aeromonas hydrophila. Fish Shellfish Immunol. 31, 564-570. doi: 10.1016/j.fsi.2011.07.006

Rodríguez, I., Novoa, B., and Figueras, A. (2008). Immune response of zebrafish (Danio rerio) against a newly isolated bacterial pathogen Aeromonas hydrophila. Fish Shellfish Immunol. 25, 239-249. doi: 10.1016/j.fsi.2008.05.002

Sambrook, J., Fritsch, E. F., and Maniatis, T. (1989). Molecular Cloning: A Laboratory Manual, 2nd Edn. Cold Spring Harbor, NY: Cold Spring Harbor Laboratory.

Sanger, F., Nicklen, S., and Coulson, A. R. (1977). DNA sequencing with chainterminating inhibitors. Proc. Natl. Acad. Sci. U.S.A. 74, 5463-5467. doi: 10.1073/pnas.74.12.5463

Saraceni, P. R., Romero, A., Figueras, A., and Novoa, B. (2016). Establishment of infection models in zebrafish larvae (Danio rerio) to study the pathogenesis of the bacteria Aeromonas hydrophila. Front. Microbiol. 7:1291. doi: 10.3389/fmicb.2016.01219
Schadich, E., and Cole, A. L. J. (2010). Pathogenicity of Aeromonas hydrophila, Klebsiella pneumoniae, and Proteus mirabilis to brown tree frogs (Litoria ewingii). Comp. Med. 60, 114-117.

Sha, J., Pillai, L., Fadl, A. A., Galindo, C. L., Erova, T. E., and Chopra, A. K. (2005). The type III secretion system and cytotoxic enterotoxin alter the virulence of Aeromonas hydrophila. Infect. Immun. 73, 6446-6457. doi: 10.1128/IAI.73.10.6446-6457.2005

Swaim, L. E., Connolly, L. E., Volkman, H. E., Humbert, O., Born, D. E., and Ramakrishnan, L. (2006). Mycobacterium marinum infection of adult zebrafish causes caseating granulomatous tuberculosis and is moderated by adaptive immunity. Infect. Immun. 74, 6108-6117. doi: 10.1128/IAI.00887-06

Tomás, J. M. (2012). The main Aeromonas pathogenic factors. ISRN Microbiol. 4:256261. doi: 10.5402/2012/256261

Tsai, C. M., and Frasch, C. E. (1982). A sensitive silver stain for detecting lipopolysaccharides in polyacrylamide gels. Anal. Biochem. 119, 115-119. doi: 10.1016/0003-2697(82)90673-X

van der Sar, A. M., Musters, R. J., van Eeden, F. J., Appelmelk, B. J., VandenbrouckeGrauls, C. M., and Bitter, W. (2003). Zebrafish embryos as a model host for the real time analysis of Salmonella typhimurium infections. Cell Microbiol. 5, 601-611. doi: 10.1046/j.1462-5822.2003.00303.x

Varela, M., Romero, A., Dios, S., van der Vaart, M., Figueras, A., Meijer, A. H., et al. (2014). Cellular visualization of macrophage pyroptosis and interleukin$1 \beta$ release in a viral hemorrhagic infection in zebrafish larvae. J. Virol. 88, 12026-12040. doi: 10.1128/JVI.02056-14

Vilches, S., Canals, R., Wilhelms, M., Saló, M. T., Knirel, Y. A., Vinogradov, E., et al. (2007). Mesophilic Aeromonas UDP-glucose pyrophosphorylase (GalU) mutants show two types of lipopolysaccharide structures and reduced virulence. Microbiology 153, 2393-2404. doi: 10.1099/mic.0.2007/006437-0

Vilches, S., Jiménez, N., Merino, S., and Tomás, J. M. (2012). The Aeromonas dsbA mutation decreased their virulence by triggering type III secretion system but not flagella production. Microb. Pathog. 52, 130-139. doi: 10.1016/j.micpath.2011.10.006

Vilches, S., Urgell, C., Merino, S., Chacón, M. R., Soler, L., Castro-Escarpulli, G., et al. (2004). Complete type III secretion system of a mesophilic Aeromonas hydrophila strain. Appl. Environ. Microbiol. 70, 6914-6919. doi: 10.1128/AEM.70.11.6914-6919.2004

Vilches, S., Wilhelms, M., Yu, H. B., Leung, K. Y., Tomás, J. M., and Merino, S. (2008). Aeromonas hydrophila AH-3 AexT is an ADP-ribosylating toxin secreted through the type III secretion system. Microb. Pathog. 44, 1-12. doi: 10.1016/j.micpath.2007.06.004

Westphal, O., and Jann, K. (1965). Bacterial lipopolysaccharide extraction with phenol-water and further application of the procedure. Methods Carbohydr. Chem. 5, 83-91.

Wong, C. Y., Mayrhofer, G., Heuzenroeder, M. W., Atkinson, H. M., Quinn, D. M., and Flower, R. L. (1996). Measurement of virulence of aeromonads using a suckling mouse model of infection. FEMS Immunol. Med. Microbiol. 15, 233-241. doi: 10.1111/j.1574-695X.1996.tb00089.x

Yu, H. B., Rao, P. S., Lee, H. C., Vilches, S., Merino, S., Tomas, J. M., et al. (2004). A type III secretion system is required for Aeromonas hydrophila AH-1 pathogenesis. Infect. Immun. 72, 1248-1256. doi: 10.1128/IAI.72.3.12481256.2004

Yu, H. B., Zhang, Y. L., Lau, Y. L., Yao, F., Vilches, S., Merino, S., et al. (2005). Identification and characterization of putative virulence genes and gene clusters in Aeromonas hydrophila PPD134/91. Appl. Environ. Microbiol. 7, 4469-4477. doi: 10.1128/AEM.71.8.4469-4477.2005

Conflict of Interest Statement: The authors declare that the research was conducted in the absence of any commercial or financial relationships that could be construed as a potential conflict of interest.

Copyright (c) 2016 Romero, Saraceni, Merino, Figueras, Tomás and Novoa. This is an open-access article distributed under the terms of the Creative Commons Attribution License (CC BY). The use, distribution or reproduction in other forums is permitted, provided the original author(s) or licensor are credited and that the original publication in this journal is cited, in accordance with accepted academic practice. No use, distribution or reproduction is permitted which does not comply with these terms. 